\title{
Pathomorphological Changes in Type-2 Diabetes in Rat Model
}

\author{
J.K. Raval*, M.C. Prasad, H.C. Parmar, J.M. Patel, P.D. Vihol and J.H. Patel \\ Department of Veterinary Pathology, Vanbandhu College of Veterinary Science and A.H, \\ Navsari Agricultural University - Navsari-396450, Gujarat, India \\ *Corresponding author
}

\begin{tabular}{|l|l|}
\hline \multicolumn{2}{c}{ A B S T R A C T } \\
\cline { 2 - 2 } $\begin{array}{l}\text { Key words } \\
\begin{array}{l}\text { Type-II diabetes, Rats, } \\
\text { Gross and } \\
\text { histopathological } \\
\text { changes, Kidney, }\end{array}\end{array}$ & $\begin{array}{l}\text { The present study was aimed for studying gross and histopathological changes } \\
\text { in various organs of STZ-NAD induced Type -II diabetic rat model. In } \\
\text { diabetic group rats, the gross changes included congestion in liver, kidneys, } \\
\text { heart and brain, atrophic changes in liver, heart, pancreas, spleen, thymus, } \\
\text { testes and epididymes, edematous mesenteric lymph nodes and ulcerations in } \\
\text { gastrointestinal tract in comparison to control group. The histopathological } \\
\text { changes consisted of reduction in number /size / cellular components of islets } \\
\text { of Langerhans and necrotic /degenerative changes in pancreas while }\end{array}$ \\
\hline $\begin{array}{l}\text { Accepted: } \\
\text { 04 October 2018 } \\
\text { Available Online: } \\
10 \text { November 2018 }\end{array}$ & $\begin{array}{l}\text { coagulative necrosis, tubular mineralization and vacuolar degeneration in } \\
\text { kidneys. }\end{array}$ \\
\hline \hline
\end{tabular}

\section{Introduction}

Type 2 diabetes mellitus is a non-autoimmune and polygenic metabolic disease in which the body fails to produce enough insulin resulting in abnormal glucose homeostasis.

The pathogenesis appears to involve complex interactions between genetic and various environmental factors (Gupta et al., 2008).

It occurs due to impaired insulin effectiveness at cellular level (Permutt et al., 2005) and is accompanied by a number of side effects involving almost all the organs resulting in diabetic retinopathy, neuropathy, nephropathy and macrovascular/ microvacular complications (viz., coronary artery disease, cerebrovascular disease and peripheral vascular disease), dyslipidemia, oxidative stress, cardiomyopathy (Anonymous, 1991; Aaron and Vinik, 2001) and poor wound healing (Lin and Sun, 2010).

\section{Materials and Methods}

\section{Chemicals and instruments}

Diabetes inducing agents i.e. Streptozotocin and Nicotinamide, Hemotoxylin and eosin stains and micro slides were purchased from Himedia Pvt. Ltd. Mumbai. The tissues were processed on Automated tissue processor (Yorko Ltd.) and stained manually. 


\section{Experimental animals}

The rats were procured from Zydus Research Centre, Ahmedabad, Gujarat and Laboratory Animal Resources (LAR), Sun Pharma Advanced Research Company Limited, Vadodara, Gujarat, India. Ethical clearances for performing the experiments on the rats were obtained from Institutional Animal Ethical Committee (IAEC) (No. 030-VCNVPP-2015.)

\section{Induction of Type-II diabetes in rats}

Type-II diabetes mellitus was induced in rats by administering Nicotinamide (NAD) and Streptozotocin (STZ). The animals were first subjected to intraperitoneal injection of NAD @ $230 \mathrm{mg} / \mathrm{kg}$ (dissolved in normal saline) followed by the administration of STZ @65 $\mathrm{mg} / \mathrm{kg}$ (dissolved in 0.1 Molar citrated buffer) intraperitoneally after 15 minutes (Masiello et al., 1998; Bisht, 2013).

Two days post STZ-NAD administration blood glucose level was estimated by glucometer to confirm diabetes.

Ten male and ten female rats with glucose level $\geq 180 \pm 8 \mathrm{mg} / \mathrm{dl}$ were considered as diabetic and were selected for the study. Control group rats were injected normal saline followed by 0.1 Molar citrated buffer.

\section{Grouping and treatment provided}

Gr. 1 consisted of 10 male and 10 female healthy rats. Gr. 2 consisted of 10 male and 10 female diabetic rats. The rats were numbered, colour marked on tail and given cage card number for easy identification.

\section{Necropsy and organ collection}

At the end of the study all the rats covering different groups were subjected to necropsy.
Prior to sacrifice the animals were fasted overnight, weighed and examined externally. The rats were sacrificed by over dose of Ether inhalation followed by cervical dislocation.

\section{Results and Discussion}

Various gross and histopathological changes in different organs were observed in the rats of different groups (Gr.1 to 5) and are described as below.

\section{Group 1 (Vehicle /Non Diabetic Control)}

\section{Gross Findings}

Gross lesion of pathological significance could not be observed in any rat belonging to this group except atrophy of thymus ( 2 males and 2 females) which might be attributed to increasing ageing process.

It has been well established that as the animal ages atrophy of thymus occurs (Boorman et al., 1990).

\section{Histopathological Findings}

Histopathological examination of liver (2 males) and kidneys (1 male) and thymus (2 males and 2 females) revealed changes. Foci of mononuclear cells infiltration were seen in liver and kidneys whereas lymphoid depletion characterised by 'starry sky appearance' was discernible in thymus.

Liver and kidneys are considered to be important detoxifying organs and during detoxifying process micronecrotic foci would have been developed. 'Starry sky appearance' in thymus could have developed due to lymphophagocytic process as a result of individual cell necrosis (Stephan et al., 1990). Further, these findings have been considered as incidental findings without any etiological agent. 


\section{Effect of diabetes}

\section{Group 2 (Streptozotocin (STZ) - Nicotinamide (NAD) Induced Diabetic Rats)}

\section{Gross findings}

Liver (6 males and 4 females), kidneys (5 males and 5 females), heart (4 males and 3 females) and brain ( 2 males and 2 females) revealed varying degree of congestion while liver ( 5 males and 3 females), heart ( 2 males and 2 females), pancreas (6 males and 4 females),spleen (6 males and 5 females), thymus (6 males and 5 females), testes (5 males), epididymides (4 males) and seminal vesicle (5 males) were found to be atrophied as compared to Gr.1. Mesenteric lymph nodes were edematous ( 6 males and 6 females) and gastrointestinal tract showed ulcerations (5 males and 5 females) in the present study.

Our findings were in support of observations made by Barr et al., (2007) who mentioned that the diabetes is associated with long-term complications affecting pancreas, heart, eyes, kidneys and nerves. Reduction in the cardiac size in present study might be due to reduction in diabetic cardiac mass over the time as opined by Renuga et al., (2013) who further assigned atherosclerosis and myocardial congestion as the hallmark of diabetic macrovascular disease. Further, changes in liver and kidneys of diabetic rats supported the observations of Sachi et al., (2002), Enas et al., (2004) and Olurishe et al., (2013).

\section{Histopathological findings}

\section{Pancreas}

Varying degree of congestion (6 males and 5 females), mononuclear cells infiltrations, degenerative /necrotic changes in exocrine pancreas, reduction in the number, size and cellular components of the islets, loss of architectural details in exocrine pancreas (6 males and 4 females) were observed on histopathological examination. A well circumscribed uniform/homogeneous eosinophilic material with complete loss of cellular details at some places were noted in pancreatic sections (6 males and 6 female). Comparable findings in terms degeneration in pancreatic acini, reduction in pancreatic islets diameter, islets count and islet cells were reported in the STZ-induced diabetic rats in comparison to control animals in earlier study done by Jana et al., (2002).

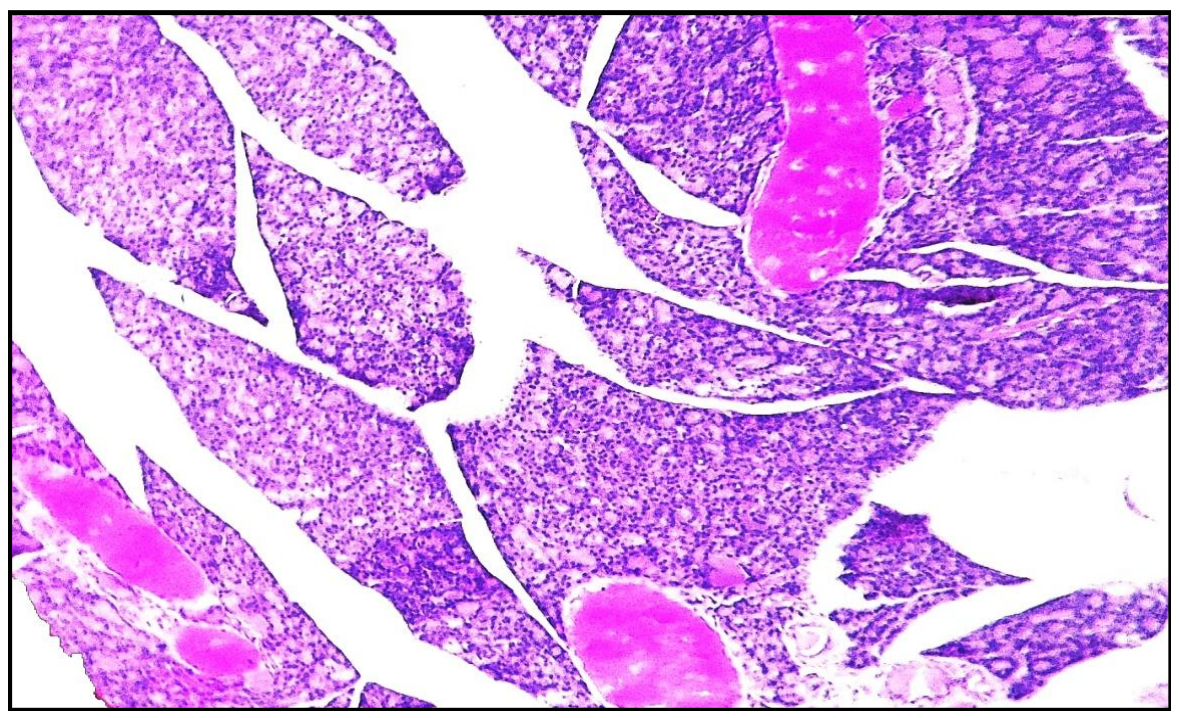

Fig.1 Histopathological findings 
Atrophy of pancreatic beta cells in alloxan induced $(150 \mathrm{mg} / \mathrm{kg}$ ip) diabetic rats was also reported by Khaled et al., (2009). Our findings strengthened the report of Fazil et al., (2010) who recorded extensive damage in the islets of Langerhans and reduced dimensions of islets in alloxan induced diabetic rats. Our findings were also in agreement with the report of Singh and Gupta (2007) who described disorganization and degranulation of islet cells, acinar hyperplasia with ballooning of cells, hydropic degeneration and fibroblastic replacement in alloxan induced diabetic rats.

The pathomorphological features seen in cattle (Taniyama, 1993), dogs and cats (Hess et al., 2000; Davison et al., 2003) were reported to be comparable to those seen in insulin dependent diabetes mellitus in human beings. Our findings were also in linearity with the report made by Barr et al., (2007) who observed amyloid deposition within islets, around capillaries and between pancreatic cells in type-2 diabetic human patients. Comparable findings like reduction in the number and size of pancreatic islets (Kaneko and Rhode, 1964; Von and Wittwer, 1986) along with vacuolar degeneration of beta cells (Baker et al., 1983) were also reported in diabetes mellitus. The histopathological changes observed in pancreas in the present study might be due to direct cytotoxic action of streptozotocin (nitrosourea moiety) used to induce diabetes as opined by Junod et al., (1967) and Ozturk et al., (1996) or due to oxidative stress associated apoptosis of pancreatic beta cells (Jana et al., 2010). We felt two possibilities about genesis of the eosinophilic structure in pancreatic sections; one might be localized amyloidosis and other the hyalinization followed by necrotic lesion. As such we could not ascertain the exact identity of the said structure without special staining. The uniform eosinophilic material occupying the islets of Langerhans in alloxan induced diabetic Wistar rats was also observed by Eliakim-Ikechukwu and Obri (2009). Nicotinamide (NAD) used STZ-NAD in diabetes induction in present study could have acted as an antioxidant thus partially protected pancreatic beta cells from cytotoxic action of streptozotocin but needs further research.

\section{Kidneys}

Kidneys showed varying degree of patchy area of congestion and mononuclear cells infiltration (5 males and 5 females), coagulative necrosis (5 males and 4 females), tubular mineralizations (5 males and 5 females), cloudy swellings (6 males and 5 females), vacuolar degenerations (6 males and 5 females), desquamation and denucleation of tubular epithelium (5 males and 5 females) and total absence of tuft of capillaries in some of the glomeruli also known as 'ghost glomeruli' in 5 males and 5 females rats belonging to this group.

Our findings supported the histopatohological observations made by Enas (2004) who described dilatation and severe engorgement of blood vessels, atrophy and swelling of glomerular tuft and cloudy swelling accompanied by hyaline cast in convoluted tubules, vacuolar degenerative changes in renal tubules, diffuse extravagations of red blood cells between degenerated renal tubules in alloxan induced diabetic rats. Sachi et al., (2002) also described nephropathy and the changes including diffuse glomerulosclerosis, thickening of basement membrane, mesangial proliferation and fibrin cap in diabetic fatty rats. In diabetic patients urinary tract infections are usually more severe associated with increased risk of complications. Patients both with Type 1 and Type 2 diabetes 
mellitus are at increased risk of urinary tract infections. Kakadiya et al., (2010) attributed hyperglycaemia as most probable contributing factor in the development of ischaemic renal failure in diabetes.

In diabetic group rats the gross changes included congestion in liver, kidneys, heart and brain, atrophic changes in liver, heart, pancreas, spleen, thymus, testes and epididymes, edematous mesenteric lymph nodes and ulcerations in gastrointestinal tract in comparison to Gr.1/control group. The histopathological changes in diabetic control group consisted of reduction in number /size / cellular components of islets of Langerhans, necrotic/degenerative changes in pancreas (uniform/homogeneous eosinophilic material with complete loss of cellular details) while coagulative necrosis, tubular mineralization and vacuolar degeneration in kidneys.

\section{Acknowledgements}

The authors are thankful to the Dean and Principal, Vanbandhu College of Veterinary Science and Animal Husbandry, Navsari and Officers of Sun Pharma Advanced Research Company Ltd. Vadodara and Zydus Research Center, Ahmedabad.

\section{References}

Aaron and Vinik. (2001). Diabetes and macrovascular disease. Journal of diabetes and its complications, 16: 23545.

Anonymous. (1991).UK Prospective Diabetes Study (UKPDS). VIII. Study design, progress and performance. Diabetologia, 34(12): 877-90.

Baker, J.S., Jackson, H.D. and Sommers, E.L. (1983). Diabetes mellitus in a four-yearold pregnant Holstein. Compend Cant Ed. Pract Vet, 5: S328-S33.

Barr, E. L., Zimmet, P. Z., Welborn T. A., D. Jolley, and Magliano, D. J. (2007). Risk of cardiovascular and all-cause mortality in individuals with diabetes mellitus, impaired fasting glucose, and impaired glucose tolerance: the Australian Diabetes, Obesity, and Lifestyle Study (AusDiab), Circulation, 116: 151-157.

Bisht. R. and Bhattacharya S. (2013). Effect of various extracts of Desmodium gangeticum on Streptozotocinnicotinamide induced type-2 diabetes. Asian Journal of Plant Science and Research, 3(3): 28-34.

Boorman, G.A, Eustis, S.L and Elwell, M.R. (1990). Pathology of the Fischer rat. Reference and atlas. Academic Press, San Diego, New York, London.

Davison, L., Ristic, J. and Herrtage, M. (2003). Anti-insulin antibodies in dogs with naturally occurring diabetes mellitus. Vet Immunol Immunopath. 91: 53-60.

Eliakim-ikechukwu, C. F. and Obri A. I. (2009). Histological changes in the pancreas following administration of ethanolic extract of Alchornea cordifolia leaf in alloxan- induced diabetic wistar rats. Nigerian journal of physiological sciences, 24 (2): 153 -155

Enas A. M. K. (2004). Biochemical and histopathological studies on the influence of aqueous extract of fenugreek seed (Trigonella foenum graecum) on alloxan diabetic male rats The Egyptian Journal of Hospital Medicine, 15:83 - 94. I.S.S.N: 12084.pp.1687-2002.

Gupta,V., Khadgawat, R., Saraswathy, K.N., Sachdeva, M.P and Kalla, A.K. (2008). Emergence of TCF7L2 as a Most Promising Gene in Predisposition of Diabetes Type II. Int. J Hum Genet, 8 (12): 199-215.

Hess, R.S, Kass, P.H and Ward, C.R. (2000). Breed distribution of diabetes mellitus in dogs admitted to a tertiary care facility. $J$ Am Vet Med Assoc. 216: 1414-1417.

Jana, K., Ghosh, A., Kanti Bera, T. and Ghosh, D. (2002). Evaluation of antidiabetic and antioxidative effect of seed of Eujenia jambolana in streptozotocin induced diabetic male rat. World Journal of 
Pharmaceutical Research, 3(6): 20402056. ISSN, $2002-7105$.

Junod, A., Lambert, A.E, Stauffacher, W. and Renold, A.E. (1967). Diabetogenic action of streptozotocin. Proc Soc Exp BiolMed, 126: 201-5.

Kakadiya, J., Shah, M. and Shah, N. (2010). Glimepiride Reduces on Experimentally Induced Ischemia/Reperfusion In Diabetic Rats. International Journal of Applied Biology and Pharmaceutical Technology, 1(2): 276-285.

Kaneko, J.J. and Rhode, E.A. (1964). Diabetes mellitus in a cow, J. Am Vet Med Assoc. 144:367-373.

Khaled, H., Serge, C., Kamel, J., Slaheddine, M., Samiha, L, Dorra, L., Fatma, A., Abdelfattah, E. (2009). 1alpha 25 dihydroxy vitamin D3: therapeutic and preventive effects against oxidative stress, hepatic, pnacratic and renal injuries in alloxan induced dibetes in rats. J. Nutr. Sci. Vitaminol, 55: 215-222.

Lin Y. and Sun, Z. (2010). Current views on type 2 diabetes. J Endocrinol. 204 (1): 111.

Masiello, P., Broca, C., Gross, R., Roye, M., Manteghetti, M. and Hillaire-Buys, D. (1998). Experimental NIDDM: Development of new model in adult rats administered streptozotocin and nicotinamide. Diabetes, 47: 224-9.

Olurishe, C.O, Salawu, O.A, Zezi, A.U, Olurishe, T.O. and Bisalla, M. (2013). Metformin-Cefixime Co-administration affects Glucose Regulation and RenoPancreatic Histology in Alloxan-induced Hyperglycemic Rats. Journal of Pharma SciTech, 3(1): 43-49.
Ozturk, Y., Atlan, V.M. and Yildizoglu-Ari, N. (1996). Effects of experimental diabetes and insulin on smooth muscle functions. Pharmacol Rev, 48: 69-112.

Permutt, M.A. Wasson, J. and Cox, N. (2005). Genetic Epidemiology of Diabetes. Journal of clinical Investigation, 115: 1431-1439.

Sachi Hoshi, Yujing Shu, Fusayo Yoshida, Tomoko Inagaki, Jiro Sonoda and Teruo Watanabe. (2002). Podocyte injury promotes progressive nephropathy in Zucker Diabetic Fatty Rats. Lab Invest, 82: 25-35.

Singh, N. and Gupta, M. (2007). Effects of Ethanolic extract of Syzygium cumini (Linn) seed powder on pancreatic islets of alloxan diabetic rats. Indian journal of experimental biology, 45: 861-867.

Stephan, F., Detlef, M. and Hans-Jochen, S. (1990). The spleen in osteomyelofibrosis A morphological and immunohistochemical study of 30 cases. Virchows Archiv A Pathol Anat, 416:437442

Taniyama, H., Shirakawa, T., Uruoka, H. F., Osame, S., Kitamura, N. and Miyazawa, K. (1993). Spontaneous Diabetes Mellitus in Young Cattle: Histological, Immunohistochemical, and Electron Microscopic Studies of the Islets of Langerhans. Vet Pathol, 30:46-54

Von, T.A. and Wittwer, F. (1986). Spontaneous diabetes mellitus Spontaner Diabetes mellitus beizwciciigcnwciblichen Zwillingsrindern. Schweiz Arch Tierheilkd, 128:475-482.

\section{How to cite this article:}

Raval, J.K., M.C. Prasad, H.C. Parmar, J.M. Patel, P.D. Vihol and Patel, J.H. 2018. Pathomorphological Changes in Type-2 Diabetes in Rat Model. Int.J.Curr.Microbiol.App.Sci. 7(11): 19-24. doi: https://doi.org/10.20546/ijcmas.2018.711.003 